\title{
COMPOSTAGEM DE RESÍDUOS DA INDÚSTRIA DE DESFIBRILAÇÃO DE ALGODÃO
}

\section{MÔNICA S. S. DE M. COSTA ${ }^{1}$, LUIZ A. DE M. COSTA ${ }^{2}$, MARCELO SESTAK ${ }^{3}$, DÁCIO OLIBONE $^{4}$, DIEGO SESTAK ${ }^{5}$, ANDERSON V. KAUFMANN ${ }^{6}$, SANDRA R. ROTTA ${ }^{7}$}

RESUMO: O processo de compostagem foi avaliado por meio do monitoramento diário da temperatura em leiras confeccionadas com o resíduo da indústria de desfibrilação de algodão e tipos de inóculo. Foram avaliadas seis leiras, divididas em dois sistemas: com aeração e sem aeração, sendo estudados, em cada sistema, três tipos de inóculo: esterco bovino diluído em água; esterco bovino, e conteúdo ruminal. Avaliou-se, também, a porcentagem de redução de volume nas leiras quando se intensificaram os revolvimentos, visando a obter informações para fins de dimensionamento do pátio de compostagem. Os compostos produzidos foram transferidos para minhocário e amostras do produto após a compostagem e após a vermicompostagem foram analisadas quimicamente com o objetivo de avaliar os teores de nutrientes. Os resultados obtidos demonstraram que o conteúdo ruminal utilizado como inóculo tende a apresentar valores mais altos de temperatura na fase inicial (fase ativa) e menores na fase final (maturação), embora, independentemente do tipo de inóculo utilizado, a estabilização praticamente tenha ocorrido no mesmo período; o sistema com aeração possibilitou, em todos os tratamentos, estabilização mais rápida do material, quando comparado ao sistema sem aeração; a intensificação dos revolvimentos possibilitou diminuição do tempo de retenção com redução de $46 \%$ no volume final, e a composição química dos vermicompostos apresentou-se enriquecida quando comparada aos compostos produzidos.

PALAVRAS-CHAVE: aeração, inóculo, vermicompostagem

\section{COMPOSTING OF COTTON INDUSTRIAL WASTE}

\begin{abstract}
The composting process performance was evaluated through diary temperature monitoring at piles made with the waste of cotton carding industry and kinds of inocule. Were evaluated six piles divided in two systems: with aeration and without aeration. In each system three kinds of inocule: cattle waste diluted in water; cattle waste and rumen were studied. In a second phase three piles with rumen intensifying the turnings aiming to evaluate the reduction of weight and volume in order to evaluate the dimension of a composting area were also conducted. All the composts produced were transferred to a earthworm creation area and samples of the product after the composting and after the vermicomposting were chemically analyzed aiming to evaluate the nutrients content. The results obtained showed that: the rumen as a inocule presents high values of temperatures in the initial phase (active phase) and low values in the final phase (maturity) although independently of the inocule the stabilization occurred at the same time; the system with aeration allowed in all treatments a faster material stabilization when compared to the system without aeration; the intensification of turnings in the second phase allowed the decreasing of the composting time and $46 \%$ of final volume reduction; the chemical composition of the vermicomposts showed enriched when compared with the composts produced.
\end{abstract}

KEYWORDS: aeration, inocule, vermicomposting.

\footnotetext{
${ }^{1}$ Eng $^{\mathrm{a}}$ Agrí́cola, Prof. Assistente, Centro de Ciências Agrárias, Curso de Agronomia, UNIOESTE, Mal. Cândido Rondon - PR, Doutoranda em Energia na Agricultura, FCA/UNESP, monicas@fca.unesp.br

${ }^{2}$ Eng $^{\text {o }}$ Agrônomo, Doutorando em Energia na Agricultura, FCA/UNESP, Botucatu, - SP, mendonca@ fca.unesp.br

${ }^{3}$ Eng ${ }^{\circ}$ Agrônomo, Goio-Erê - PR.

${ }^{4}$ Eng $^{\mathrm{o}}$ Agrônomo, Mestrando em Agricultura, FCA/UNESP, Botucatu - SP.

${ }^{5}$ Zootecnista, UNIOESTE, Mal. Cândido Rondon - PR.

${ }^{6}$ Eng $^{\circ}$ Agrônomo, UNIOESTE, Mal. Cândido Rondon - PR.

${ }^{7}$ Eng $^{\mathrm{a}}$ Agrônoma, Mestre, Cascavel - PR.

Recebido pelo Conselho Editorial em: 26-5-2003

Aprovado pelo Conselho Editorial em: 7-6-2005
}

Eng. Agríc., Jaboticabal, v.25, n.2, p.540-548, maio/ago. 2005 


\section{INTRODUÇÃO}

O processo de compostagem visa a acelerar a decomposição do material orgânico desde que se tenham condições ótimas para o desenvolvimento microbiano. Basicamente, a temperatura, aeração, umidade, relação carbono:nitrogênio e nutrientes são os fatores que mais interferem no processo de compostagem.

De forma geral, todos os resíduos orgânicos, de origem vegetal ou animal, podem ser submetidos ao processo de compostagem, sendo seu desempenho estabelecido pelas condições existentes no meio.

O processo de compostagem tem sido utilizado como alternativa para a disposição ambientalmente correta de resíduos oriundos de diferentes atividades agrícolas, agroindustriais e industriais. VITORINO \& PEREIRA NETO (1996) estudaram a compostabilidade dos resíduos da agroindústria sucroalcooleira. MALHEIROS \& PAULA JÚNIOR (1997) trabalharam com resíduos agroindustriais, como esterco bovino, torta de filtro e casca de pínus e resíduo de lã de carneiro, normalmente descartado em aterros sanitários; DECARLI (1999) utilizou resíduos provenientes de abatedouros, constituídos de vísceras e descartes do abate de suínos e bovinos; AUSINA et al. (2000) realizaram compostagem de materiais orgânicos (casca de café, fino de carvão vegetal, casca de arroz, serragem de madeira, bagaço de cana-de-açúcar e sabugo de milho triturado) com água residuária da suinocultura; SILVA et al. (2000) estudaram o processo de compostagem com carcaças de frango e cama de aviário.

Além da compostagem, outra maneira eficiente de reciclar resíduos sólidos é a vermicompostagem. Segundo KIEHL (1985), a vermicompostagem é uma tecnologia na qual se utilizam as minhocas para digerir a matéria orgânica, provocando sua degradação. Para MARTINEZ (1992), os produtos orgânicos resultantes da agroindústria, bem como os da indústria manufatureira, podem ser compostados e fornecidos como alimento para as minhocas.

Os resíduos da indústria de desfibrilação de algodão apresentam-se sólidos, na forma de pequenos fragmentos, com granulometria fina e relação C:N em torno de 20:1. Nessas condições, o processo de compostagem pode ser utilizado, bastando estabelecer alguns parâmetros, como aeração, turno de rega e revolvimentos. A utilização de inóculo nesse tipo de resíduo torna-se um complemento importante para ativar o processo de decomposição. Entretanto, para que haja viabilização econômica do processo, recomenda-se a utilização de resíduos ricos em microrganismos, como os estercos, e que estejam disponíveis nas proximidades do local de geração do resíduo que se pretende reciclar.

Quanto a relatos referentes à compostagem e à vermicompostagem de resíduos provenientes da indústria de desfibrilação de algodão, são mais comuns os encontrados em literatura estrangeira, utilizando-se de caroço e de capulho de algodão no processo de compostagem.

PAREDES et al. (1996) estudaram as transformações do $\mathrm{N}$ durante a compostagem de resíduos de algodão com lodo de esgoto e resíduos de algodão com esterco de aves; KIRCHMANN \& BERNAL (1997) confeccionaram pilhas de compostagem com injeção de ar, utilizando mistura de lodo de esgoto (46,5\%) e resíduo de algodão (53,5\%); BERNAL et al. (1998) avaliaram parâmetros de maturação e estabilização de compostos preparados com resíduos de algodão; SHERMAN (1999) descreve as operações de compostagem e vermicompostagem com resíduos de algodão e cavacos de madeira; PAULI (1999) estuda a compostagem de resíduos agroindustriais, incluindo caroço de algodão, e avaliando a produção de minhocas nesses substratos; TEJADA et al. (2001) avaliaram o processo de compostagem de resíduos provenientes do descaroçamento de algodão previamente moído ou não; MADEJÓN et al. (2001) estudaram alguns parâmetros durante a compostagem do bagaço de uva e de resíduos do descaroçamento do algodão misturados com vinhoto.

Nesta pesquisa, teve-se o objetivo de avaliar o processo de compostagem em resíduos sólidos da indústria de desfibrilação de algodão, utilizando-se de três inóculos em dois sistemas, com e sem 
injeção de ar, bem como determinar a porcentagem de redução de volume da massa de compostagem com a intensificação dos revolvimentos, e avaliar a composição química do material produzido quando submetido ou não à vermicompostagem.

\section{MATERIAL E MÉTODOS}

A pesquisa foi realizada na Fazenda Experimental da UNIOESTE - Câmpus de Marechal Cândido Rondon - PR, localizada a 24³3"40'S, 5404"'12'W, altitude de $420 \mathrm{~m}$, com temperaturas médias de $14{ }^{\circ} \mathrm{C}$ na época mais fria e $28{ }^{\circ} \mathrm{C}$ na época mais quente, e precipitação média anual de $1.800 \mathrm{~mm}$. Os resíduos da desfibrilação de algodão foram provenientes da Indústria FIASUL S.A., localizada no município de Toledo - PR, sendo o experimento conduzido em três etapas.

\section{1ำ Etapa: aeração e inóculos}

Foram confeccionadas seis leiras, em local protegido, com dimensões de 2,50 $\mathrm{m}$ de comprimento por $1,30 \mathrm{~m}$ de largura e $1,20 \mathrm{~m}$ de altura, contendo $250 \mathrm{~kg}$ do resíduo de algodão. Os inóculos utilizados nas leiras de compostagem foram esterco bovino diluído em água na proporção de $1 \mathrm{~kg}$ de esterco para $9 \mathrm{~kg}$ de água (1:10); esterco fresco de bovino e conteúdo ruminal, ambos adicionados na razão de $1 / 3$ do total de resíduos de algodão, ou seja, $83 \mathrm{~kg}$, totalizando $333 \mathrm{~kg}$ cada leira.

O sistema de aeração foi instalado em três das seis leiras, sendo constituído de uma turbina com motor elétrico de $0,5 \mathrm{cv}$ de potência, a qual injetava o ar em uma barra de PVC com $100 \mathrm{~mm}$ de diâmetro, da qual derivam outras três barras iguais, porém, perfuradas, que conduziam o ar para dentro das leiras. Com relação à quantidade de ar injetado nas leiras, intercalaram-se turnos de aeração de 15 minutos pela manhã, 15 minutos às 12 horas e 15 minutos após a determinação da temperatura, por volta das 18 horas, totalizando 45 minutos de aeração por dia.

As leiras foram constituídas da seguinte maneira: sem aeração + esterco bovino diluído (SAED); com aeração + esterco bovino diluído (CAED); sem aeração + esterco bovino in natura (SAE); com aeração + esterco bovino in natura (CAE); sem aeração + conteúdo ruminal bovino (SACR) e com aeração + conteúdo ruminal bovino (CACR).

A temperatura nas leiras de compostagem foi medida diariamente com o auxílio de termômetros de mercúrio, em seis pontos, a $40 \mathrm{~cm}$ de profundidade.

Foram realizados três revolvimentos nessa etapa do experimento, o primeiro aos 15 dias após a confecção. As regas foram diferenciadas de acordo com os tratamentos, sendo a umidade ajustada para $60 \%$ do total de massa.

\section{$2^{\text {a }}$ Etapa: redução do volume da massa de compostagem}

Confeccionaram-se três leiras, com $300 \mathrm{~kg}$ de algodão e $100 \mathrm{~kg}$ de conteúdo ruminal bovino, sem injeção de ar, sendo as mesmas revolvidas aos três, sete e dez dias após a confecção, adicionandose, em cada revolvimento, água suficiente para atingir $60 \%$ de umidade. No $14^{\circ}$ e no $35^{\circ}$ dia, promoveram-se o revolvimento e a pesagem das leiras antes da adição de água; em seguida, as leiras foram montadas e umedecidas para a determinação do volume, por meio de cubicagem. No $21^{\circ}$ dia, as leiras foram novamente revolvidas e umedecidas. A última avaliação de volume e peso das leiras deuse no $45^{\circ}$ dia, quando, então, se considerou o composto estabilizado.

\section{$3^{\text {a }}$ Etapa: vermicompostagem}

Os compostos produzidos na primeira etapa do experimento foram misturados de acordo com o inóculo utilizado e independentemente do sistema de aeração. Após homogeneização, os materiais foram colocados em três minhocários contendo espécies de Eisenia foetida, onde permaneceram por 30 dias até a formação do vermicomposto. Em seguida, os materiais foram analisados quimicamente 
com a finalidade de avaliar seu poder fertilizante. Para tanto, coletou-se uma amostra homogênea dos materiais, a qual foi enviada para o Laboratório de Química Agrícola e Ambiental da UNIOESTE. Para a determinação da umidade $\left(60-65^{\circ} \mathrm{C}\right)$ das amostras, utilizou-se da metodologia descrita por KIEHL (1985). Para as demais determinações analíticas, as amostras foram secas em estufa de circulação forçada a $60{ }^{\circ} \mathrm{C}$, triturando-se em moinho e analisadas. A porcentagem de $\mathrm{C}$ orgânico foi determinada pelo método WALKLEY \& BLACK (1944), citados por KIEHL (1985). A determinação de N, P, K, Ca e Mg foi feita de acordo com metodologia descrita em TEDESCO et al. (1985). A determinação do índice $\mathrm{pH}$ em $\mathrm{H}_{2} \mathrm{O}$ deu-se conforme descrito por KIEHL (1985).

\section{RESULTADOS E DISCUSSÃO}

Pode-se observar pela Figura 1 (a e b) que os valores de temperatura são sempre maiores nos tratamentos sem aeração do que naqueles em que se injetou ar. PEREIRA NETO (1996) cita que a aeração tem por finalidade suprir a demanda de oxigênio da população microbiana e atuar como agente de controle da temperatura, podendo ser feita de modo natural, por revolvimentos da massa, ou artificial, por injeção ou aspiração de ar, ou seja, de forma mecânica. Segundo KIEHL (1985), a abundância de ar acelera a decomposição e dá condições de melhor condução do processo, não ocorrendo mau cheiro nem atraindo moscas, podendo esse fornecimento ser melhorado com o uso de pisos permeáveis, tubulações dispostas no interior das leiras ou mesmo pela perfuração dessas. Pode-se observar que o sistema com aeração, independentemente do inóculo utilizado, estabilizou-se mais rapidamente quando comparado ao sistema sem injeção de ar. Essa estabilização pode ser observada pelos valores médios de temperatura próximos a ambiente, indicativo de que o processo entra em estabilização (KIEHL, 1985).
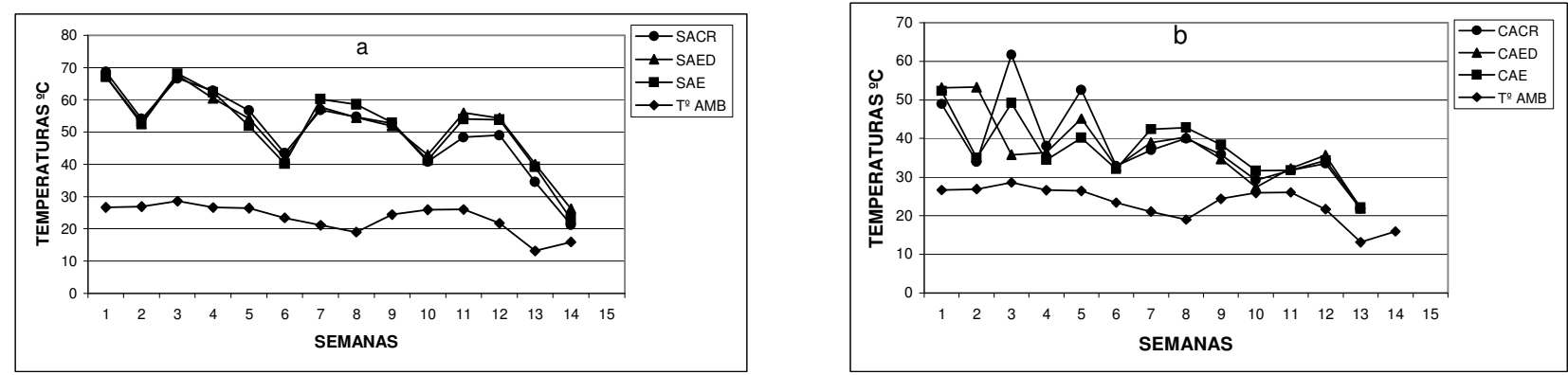

FIGURA 1. Temperaturas médias, em ${ }^{\circ} \mathrm{C}$, obtidas em leiras de compostagem com diferentes inóculos, com aeração (a) e sem aeração (b).

Observa-se que a temperatura no sistema sem aeração apresenta comportamento similar para os diferentes inóculos utilizados, enquanto, no sistema com aeração, principalmente no início do processo, a utilização do conteúdo ruminal promoveu temperaturas maiores até aproximadamente a sexta semana.

A diferença de temperatura entre os inóculos, quando se utilizou aeração, pode ser visualizada na Figura 2 (a, b e c).

As diferenças nos valores apresentados nos dois sistemas são reflexos do efeito da aeração no controle da temperatura na massa de compostagem. Nesse sentido, PEREIRA NETO (1996) comenta que o valor médio ideal da temperatura nos processos de compostagem é de $55^{\circ} \mathrm{C}$ e que temperaturas superiores a $65^{\circ} \mathrm{C}$ devem ser evitadas por causarem a eliminação dos microrganismos mineralizadores responsáveis pela degradação dos resíduos orgânicos. A manutenção de temperaturas termofílicas (45$65^{\circ} \mathrm{C}$ ) controladas, na fase de degradação ativa ( $1^{\underline{a}}$ fase do processo), é um dos requisitos básicos, uma vez que somente por meio desse controle é que se pode conseguir o aumento da eficiência do processo, ou seja, o aumento da velocidade de degradação e a eliminação dos microrganismos patogênicos. Nas 
Figuras apresentadas, pode-se observar que as leiras com aeração apresentam temperaturas variando entre 50 e $55^{\circ} \mathrm{C}$ nas primeiras semanas (fase ativa), ao mesmo tempo em que as leiras sem aeração apresentam temperaturas maiores. Salienta-se, ainda, que a leira onde se utilizou conteúdo ruminal, apresentou temperaturas dentro da faixa citada, por um período mais longo (Figura 2).
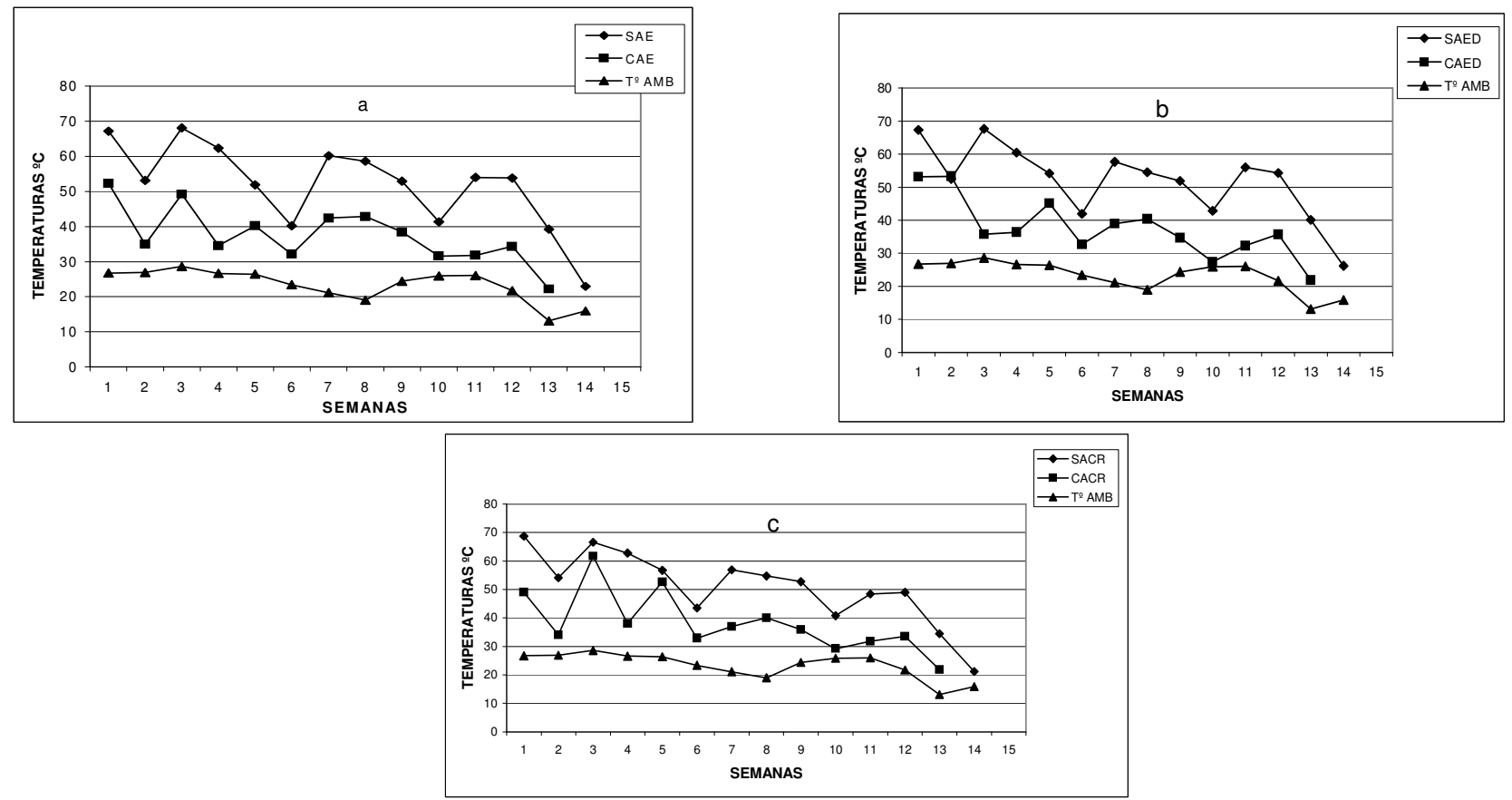

FIGURA 2. Temperaturas médias, em ${ }^{\circ} \mathrm{C}$, em leiras de compostagem com e sem aeração, inóculo de esterco bovino (a), esterco bovino diluído (b) e conteúdo ruminal (c).

O efeito da presença de ar sobre o tipo de inóculo utilizado deve-se, provavelmente, à maior atividade microbiana existente no conteúdo ruminal. Nesse resíduo, o conteúdo de $\mathrm{C}$ pouco digerido é maior do que no esterco, apresentando-se como alimento aos microrganismos e em processo de decomposição quando adicionado ao resíduo de algodão nas leiras. Assim, o processo inicia-se mais rapidamente com a presença desse inóculo. Por outro lado, o esterco apresenta maiores teores de nutrientes (Tabela 1), o que faz com que não haja grandes diferenças no que diz respeito ao final do processo (maturação). PEREIRA NETO (1994) comenta que o crescimento e a diversificação da população microbiana na massa de compostagem relaciona-se diretamente com a concentração de nutrientes, os quais fornecem material para síntese protoplasmática e suprem a energia necessária para o crescimento celular, além de outras funções.

Com relação ao $\mathrm{pH}$ dos compostos obtidos, observa-se que, independentemente do inóculo utilizado, os valores encontrados estão acima da neutralidade, característica dos compostos estabilizados. Outros trabalhos em que se utilizaram diferentes tipos de resíduo também apresentam valores de pH na faixa alcalina (GEORGACAKIS et al., 1996; BERNAL et al., 1998; VILLAS BÔAS et al., 1999 e TEJADA et al., 2001).

Segundo KIEHL (1985), esse parâmetro fornece boa informação sobre o estado de decomposição da matéria orgânica que foi submetida a um processo de fermentação. Para efeito de interpretação prática, no processo de compostagem, considera-se que matéria-prima crua tem reação ácida; quando neutra ou quase neutra, indica que o composto está bioestabilizado; o composto humificado apresentará, obrigatoriamente, reação alcalina. Essa informação fornecida pelo pH deve ser complementada por outras, como a relação C:N. 
TABELA 1. Composição química média dos resíduos/inóculos, compostos e vermicompostos produzidos.

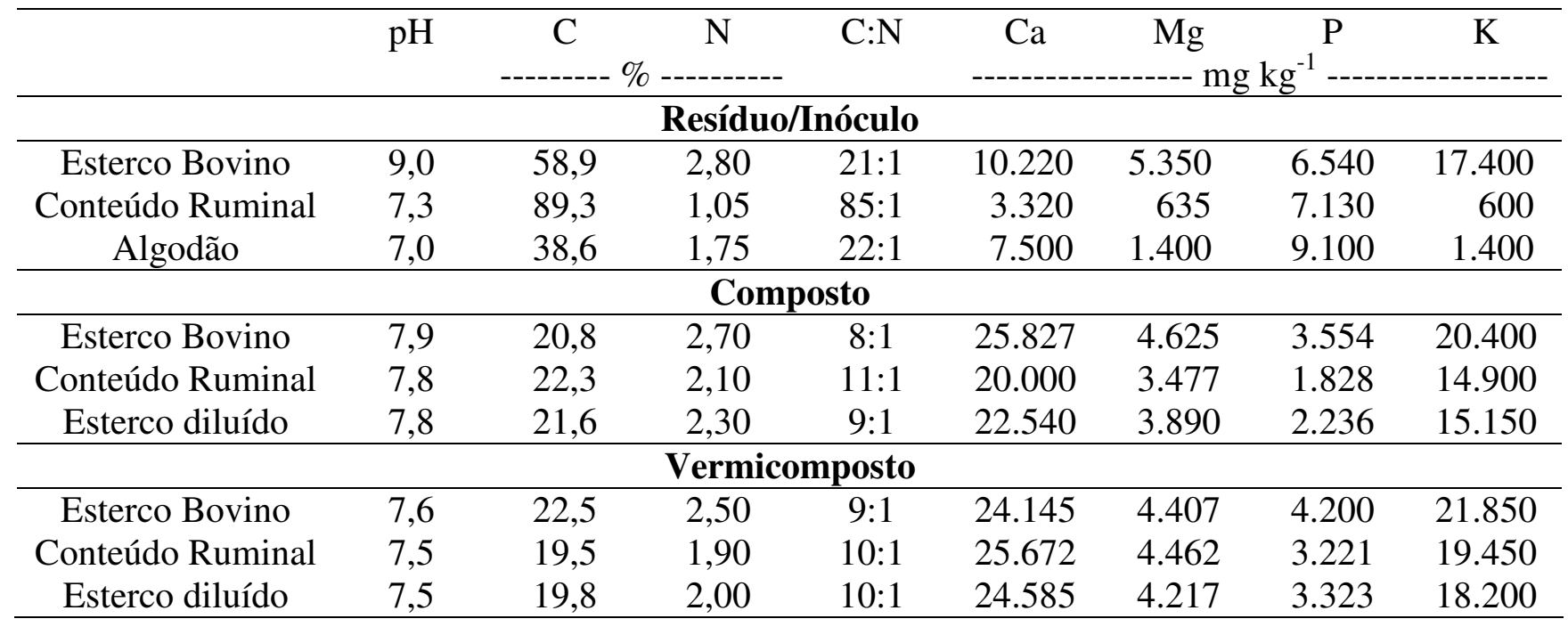

Nesse sentido, pode-se observar que a relação C:N dos compostos produzidos encontra-se dentro da faixa recomendada para considerar um composto estabilizado. KIEHL (1985) comenta que a matéria orgânica bioestabilizada é caracterizada, dentre outros parâmetros, exatamente pelo fato de apresentar relação $\mathrm{C}: \mathrm{N}$ que indica o início do processo de mineralização do nitrogênio e, para o húmus, esse valor está em torno de 10:1. VITORINO \& PEREIRA NETO (1994) verificaram redução da relação C:N para valores em torno de 10:1, em experimento com resíduos da agroindústria sucroalcooleira utilizando inóculo com esterco bovino.

Com relação às concentrações de $\mathrm{Ca}, \mathrm{Mg}, \mathrm{P}$ e $\mathrm{K}$, observa-se que o composto em que se utilizou de esterco sem diluição como inóculo, os valores apresentaram-se maiores se comparados aos outros dois tratamentos (conteúdo ruminal e esterco diluído).

De maneira geral, pode-se dizer que a concentração de nutrientes no composto dependerá da composição química do resíduo e do inóculo utilizado. GEOGACAKIS et al. (1996) realizaram compostagem de resíduos de algodão + fase sólida de esterco de suíno + lignita. A composição química do composto obtido em $\mathrm{mg} \mathrm{kg}^{-1}$ foi a seguinte: $\mathrm{Ca}=49.200 ; \mathrm{Mg}=11.400 ; \mathrm{P}=2.500$; $\mathrm{K}=7.000$. Para o $\mathrm{pH}$, o valor encontrado foi de 7,65 e para o $\mathrm{C}(\%)=11,46$. MADEJÓN et al. (2001) realizaram experimento com resíduo de algodão e vinhaça proveniente da obtenção de açúcar de beterraba. A composição química do composto obtido foi a seguinte: $\mathrm{N}(\%)=1,62 ; \mathrm{C}: \mathrm{N}=12: 1$; $\mathrm{Ca}\left(\mathrm{mg} \mathrm{kg}^{-1}\right)=52.200 ; \mathrm{Mg}\left(\mathrm{mg} \mathrm{kg}^{-1}\right)=5.500 ; \mathrm{P}\left(\mathrm{mg} \mathrm{kg}^{-1}\right)=14.061 ; \mathrm{K}\left(\mathrm{mg} \mathrm{kg}^{-1}\right)=14025$.

Com relação aos vermicompostos produzidos, observa-se, pelos valores da Tabela 1, aumento dos teores dos elementos $\mathrm{P}$ e $\mathrm{K}$ da ordem de 18,2\%; 76,2\% e 48,6\% para $\mathrm{P}$ nas leiras com esterco bovino, conteúdo ruminal e esterco diluído, respectivamente, e 7,1\%;30,5\% e 20,1\% para K nas leiras com esterco, conteúdo ruminal e esterco diluído, respectivamente.

Para os valores de $\mathrm{pH}$, observa-se pequena redução em todas as leiras, os quais não são correlacionados com os teores de $\mathrm{Ca}$ e $\mathrm{Mg}$. Para esses elementos, apenas na leira com esterco observase redução de 6,5\% de $\mathrm{Ca}$ e 4,7\% de $\mathrm{Mg}$. Nos demais tratamentos, obtiveram-se aumentos da ordem de $28,36 \%$ em Ca e 28,33\% em Mg para as leiras com conteúdo ruminal, e 9,1\% em Ca e 8,4\% em Mg para a leira com esterco diluído.

A redução do peso e do volume dos resíduos após o processo de compostagem dá-se devido às perdas de C efetuadas pela biomassa microbiana. Segundo KIEHL (1985), os microrganismos utilizam 
os elementos $\mathrm{C}$ e $\mathrm{N}$ em uma proporção de 30 partes de $\mathrm{C}$ para cada parte de $\mathrm{N}$. O C é utilizado como fonte de energia, sendo 10 partes incorporadas ao protoplasma celular e 20 partes eliminadas como $\mathrm{CO}_{2}$; o $\mathrm{N}$ é assimilado na estrutura, na proporção de dez partes de $\mathrm{C}$ para uma de $\mathrm{N}$.

Na Tabela 2, pode-se analisar a redução de peso e volume das leiras de composto durante o período avaliado.

TABELA 2. Redução de volume e peso na massa de compostagem.

\begin{tabular}{|c|c|c|c|c|c|c|c|c|}
\hline \multirow[t]{2}{*}{ Repetição } & \multicolumn{2}{|c|}{ Montagem } & \multicolumn{2}{|c|}{$\begin{array}{c}1^{\text {a }} \text { Pesagem } \\
14 \text { dias }\end{array}$} & \multicolumn{2}{|c|}{$\begin{array}{c}2^{\mathrm{a}} \text { Pesagem } \\
35 \text { dias }\end{array}$} & \multicolumn{2}{|c|}{$\begin{array}{c}3^{\mathrm{a}} \text { Pesagem } \\
45 \text { dias }\end{array}$} \\
\hline & $\mathrm{kg}$ & $\mathrm{m}^{3}$ & $\mathrm{~kg}$ & $\mathrm{~m}^{3}$ & $\mathrm{~kg}$ & $\mathrm{~m}^{3}$ & $\mathrm{~kg}$ & $\mathrm{~m}^{3}$ \\
\hline 1 & 302 & 2,20 & 264 & 1,98 & 222 & 1,45 & 214 & 1,20 \\
\hline 2 & 302 & 2,40 & 259 & 2,08 & 220 & 1,52 & 212 & 1,27 \\
\hline 3 & 302 & 2,30 & 276 & 1,91 & 224 & 1,49 & 216 & 1,25 \\
\hline Média & 302 & 2,30 & 266 & 1,99 & 222 & 1,48 & 214 & 1,24 \\
\hline \% de Redução & 100 & 100 & 12 & 14 & 27 & 36 & 30 & 46 \\
\hline
\end{tabular}

A intensificação dos revolvimentos promoveu maior rapidez na degradação aeróbia do resíduo. Esse procedimento resultou em tempo de compostagem inferior ao obtido no primeiro ensaio e em menos de 45 dias, o composto já se encontrava estabilizado. Nesse sentido, duas questões são importantes. Embora a diminuição do tempo de compostagem com a realização de revolvimentos permita dimensionar área menor para o pátio de compostagem, o fator mão-de-obra pode tornar a atividade inviável economicamente. Neste experimento, os revolvimentos foram realizados manualmente com auxílio de pás e garfos, porém não se descarta a utilização de máquinas, embora, além do aumento do custo com combustíveis, o próprio resíduo apresenta peculiaridades que exigem maquinaria adequada.

Por ser um resíduo com granulometria bastante fina, nos primeiros revolvimentos, houve a necessidade de desmanchar as placas formadas pela compactação natural das leiras. Esse procedimento exige máquinas que simulem essa atividade, desmanchando as placas que se formam e, ao mesmo tempo, aerando o material, permitindo melhor homogeneização do algodão com o inóculo.

A injeção de ar nas leiras também favorece a diminuição do tempo de compostagem, como observado pelos dados de temperatura anteriormente apresentados. Porém, os revolvimentos são imprescindíveis no tocante à homogeneização.

\section{CONCLUSÕES}

A injeção de ar nas pilhas de composto beneficiou o processo, apresentando diminuição do tempo de compostagem e do número de revolvimentos.

A utilização de conteúdo ruminal como inóculo acelerou o processo de decomposição do resíduo de algodão na fase inicial, embora, no final do processo, todos os inóculos tenham apresentado o mesmo tempo de maturação.

A utilização de esterco sem diluição como inóculo possibilitou a produção de um composto mais rico em nutrientes que inóculos com esterco diluído e conteúdo ruminal.

A vermicompostagem com composto de resíduos da desfibrilação de algodão é possível e possibilita a produção de um produto mais rico em nutrientes quando comparado ao composto, além da produção de minhocas. 
A intensificação dos revolvimentos nas leiras diminuiu o tempo de compostagem, porém pode representar aumento nos custos com mão-de-obra.

A redução média de volume nas leiras de compostagem foi da ordem de $46 \%$ em um período de 45 dias.

\section{REFERÊNCIAS}

AUSINA, M.C.; MATOS, A.T.; SEDIUAMA, M.A.N.; COSTA, L.M. Dinâmica da decomposição de resíduos orgânicos. In: CONGRESSO BRASILEIRO DE ENGENHARIA AGRÍCOLA, 29., 2000, Fortaleza. Anais... Fortaleza: Sociedade Brasileira de Engenharia Agrícola, 2000. 1 CD ROM BERNAL, M.P.; PAREDES, C.; SANCHEZ-MONEDERO, M.A.; CEGARRA, J. Maturity and stability parameters of composts prepared with a wide range of organic wastes. Bioresource Technology, Kidlington, v.63, n.1, p.91-9, 1998.

DECARLI, L. Desenvolvimento de metodologia para compostagem de resíduos sólidos de frigorífico. 1999. 66 f. Monografia (Trabalho de Graduação em Agronomia) - Universidade Estadual do Oeste do Paraná, Marechal Cândido Rondon, 1999.

GEORGACAKIS, D.; TSAVDARIS, A.; BAKOULI, J.; SYMEONIDIS, S. Composting solid swine manure and lignite mixtures with selected plant residues. Bioresource Technology, Kidlington, v.56, n.1, p.195-200, 1996.

KIEHL, E. J. Fertilizantes orgânicos. Piracicaba: Agronômica Ceres, 1985. 492 p.

KIRCHMANN, H.; BERNAL, M.P. Organic waste treatment and C stabilization efficiency. Soil Biology \& Biochemistry, Exeter, v.29, n.11/12, p.1747-53, 1997.

MADEJÓN, E.; DÍAZ, M.J.; LÓPEZ, R.; CABRERA, F. Co-composting of sugarbeet vinasse: influence of the organic matter nature of the bulking agents used. Bioresource Technology, Kidlington, v.76, n.1, p.275-8, 2001.

MALHEIROS, S.M.P.; PAULA JÚNIOR, D.R. Utilização de resíduos agroindustriais no processo de compostagem. In: CONGRESSO BRASILEIRO DE CIÊNCIA DO SOLO, 26., 1997. Rio de Janeiro. Anais...Rio de janeiro: Sociedade Brasileira de Ciência do Solo, 1997. 1 CD ROM.

MARTINEZ, A.A. A grande e poderosa minhoca: manual prático do minhocultor. Jaboticabal: FUNEP, 1992. $101 \mathrm{p}$.

PAREDES, C.; BERNAL, M.P.; CEGARRA, J.; ROIG, A. Nitrogen transformation during the composting of different organic wastes. In: NITROGEN WORKSHOP - PROGRESS IN NITROGEN CYCLING STUDIES, 8., 1996, Ghent. Proceedings... Ghent: University of Ghent, 1996. p.121-5.

PAULI, G. Earthworms, mushrooms and zero waste in China. Biocycle, Emmaus, v.40, n.2, p.68-9, 1999.

PEREIRA NETO, J.T. Tratamento, reciclagem e impacto ambiental de dejetos agrícolas. In: CONFERÊNCIA SOBRE AGRICULTURA E MEIO AMBIENTE, 1., 1992, Viçosa. Anais... Viçosa MG: UFV-NEPEMA, 1994. p.61-74.

PEREIRA NETO, J.T. Manual de compostagem: processo de baixo custo. Belo Horizonte: UNICEF, 1996. $56 \mathrm{p}$.

SHERMAN, R. Composting and vermicomposting at correctional facilities. Biocycle, Emmaus, v.40, n.7, p.34-7, 1999. 
SILVA, M.S.; COSTA, L.A.M.; LUCAS JÚNIOR, J.; SANTOS, T.M.B.; PELÁ, A.; SILVA, C.J.; DECARLI, L.D.; MATTER, U.F.; BURIN, A.; KAUFMANN, A.V.; RÖDER, C.; OLIBONE, D.; ORTOLAN, M.L. Avaliação de quatro sistemas de compostagem de animais mortos em sistemas avícolas. In: CONGRESSO BRASILEIRO DE ENGENHARIA AGRÍCOLA, 29., 2000, Fortaleza. Anais...Fortaleza: Sociedade Brasileira de Engenharia Agrícola, 2000. 1 CD ROM.

TEDESCO, M.J.; VOLKWEISS, S.J.; BOHNEN, H. Análises de solo, plantas e outros materiais. Porto Alegre: UFRGS, 1985. 188 p. (Boletim Técnico, 5)

TEJADA, M.; DOBAO, M.M.; BENITEZ, C.; GONZALEZ, J.L. Study of composting of cotton residues. Bioresource Technology, Kidlington, v.79, n.1, p.199-202, 2001.

VILLAS BÔAS, R.L.; PASSOS, J.C.; BÜLL, T.; FERNANDES, D.M. Efeito de doses e tipos de composto orgânico na produção de alface (Lactuca sativa L.). In: CONGRESSO BRASILEIRO DE CIÊNCIA DO SOLO, 27., 1999, Brasília. Anais... Brasília: Sociedade Brasileira de Ciência do Solo, 1999. 1 CD ROM.

VITORINO, K.M.N.; PEREIRA NETO, J.T. Estudo da compostabilidade dos resíduos da agricultura sucroalcooleira. In: CONFERÊNCIA SOBRE AGRICULTURA E MEIO AMBIENTE, 1., 1992, Viçosa. Anais... Viçosa- MF: UFV-NEPEMA, 1994. p.121-32. 